\title{
Rare Case of Long Standing Foreign Body in Maxillary Sinus
}

\author{
Ashish Katarkar, Modi Bhavesh, Datt Modh, Pankaj Shah
}

\section{ABSTRACT}

Foreign body in maxillary sinus is not uncommon. Case reports published worldwide have been reviewed. We present a case which was suggestive of carcinoma of maxillary sinus, but it was foreign body 'stone' in right maxillary sinus which was almost 30 years old.

Keywords: Foreign body, Stone, Maxillary sinus.

How to cite this article: Katarkar A, Bhavesh M, Modh D, Shah P. Rare Case of Long Standing Foreign Body in Maxillary Sinus. Clin Rhinol An Int J 2013;6(2):110-112.

\section{Source of support: Nil}

Conflict of interest: None declared

\section{INTRODUCTION}

Foreign body of maxillary sinus is not that uncommon. Case reports published worldwide were reviewed. The most common foreign bodies were endogenous foreign body like teeth or exogenous foreign body like gutta-percha, dental implants, ${ }^{1}$ etc. Uniqueness of the present case is in the fact that there was a history of facial trauma by a stone before 30 years. Patient presented with complaint of only 15 days.

\section{CASE REPORT}

A 45 years male patient belonging to lower socioeconomic status and working as a laborer, residing in a small town was presented to the ENT Department. The patient had a history of swelling on the right side of cheek and pain on the right side of face for 15 days. The swelling had increased gradually for last 15 days. There was no history of fever, epistaxis, nasal obstruction, nasal discharge ${ }^{2}$ or headache. Clinical examination revealed a warm, tender and firm swelling over the right side of cheek suggestive of an abscess. On anterior rhinoscopy no mass, polyp, foreign body or mucopus was seen. All required hematological and biochemical investigations were done. These were not indicative of any specific pathology.

Plain radiograph of paranasal sinuses showed $2 \times 1 \mathrm{~cm}$ radiopaque shadow in right maxillary sinus, destruction of inferior and anterolateral wall suggestive of carcinoma of maxilla as seen in Figure 1. Computed tomographic (CT) scan of paranasal sinuses was done which revealed radiopaque shadow ${ }^{3}$ with breach in inferior and anterolateral wall of maxilla, suggestive of carcinoma of maxilla (Fig. 2). But looking to the density it was suspected as stone or tooth.

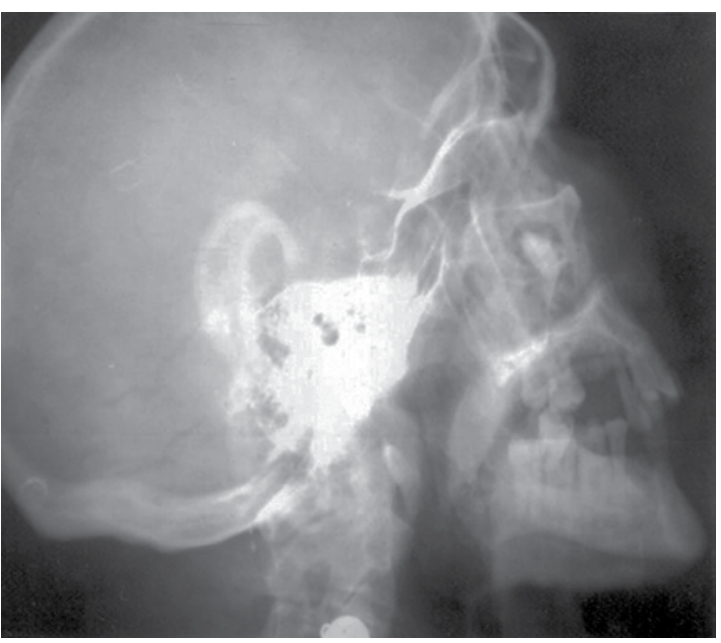

Fig. 1: Plain radiograph of paranasal sinuses showing radiopaque shadow in right maxillary sinus, destruction of inferior and anterolateral wall

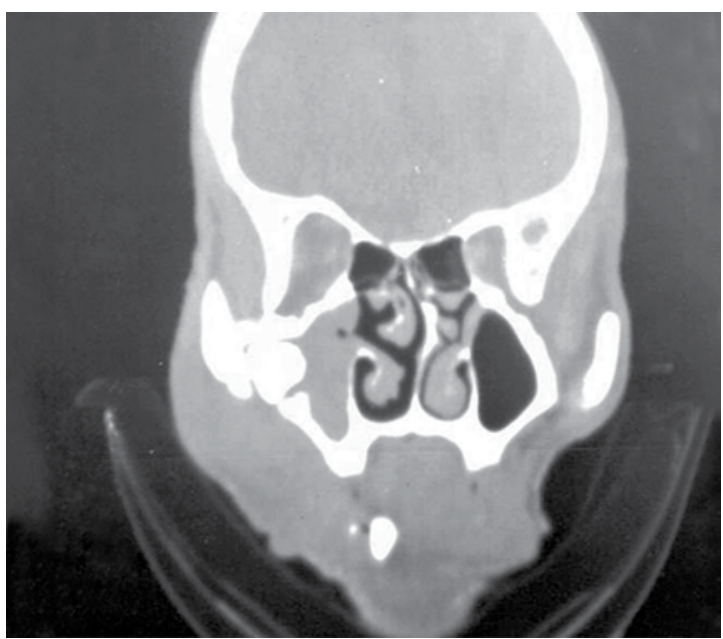

Fig. 2: Computed tomographic (CT) scan of paranasal sinuses revealed radiopaque shadow ${ }^{3}$ with breach in inferior and anterolateral wall of maxilla

Patient was operated under general anesthesia by Caldwell-Luc approach, maxillary sinus was opened. There was a stone embedded in posterior part of anterolateral wall surrounded by granulation tissue. The tissue was sent for histopathological examination and the stone was sent for the biochemical analysis. Histopathology was suggestive of chronic inflammatory tissue. The biochemical analysis of the specimen showed the presence of silica and iron in high quantities as details given below:

Antral wall specimen: 1; Si: 515.8 ppm, P: nil; Cl: nil; S: nil; Ca: 6.71\%; V: 102.1 ppm; Mn: 40.8 ppm; Fe: 7,050.2 ppm; Cu: 15.1 ppm; Zn: 67.0 ppm; Sr: 407.3 ppm. 
The findings are in favor of long standing foreign body. Postoperative recovery was uneventful. Patient was followed up for 1 year and had not presented with any features of recurrence.

\section{DISCUSSION AND CONCLUSION}

Foreign bodies and antroliths of maxillary ${ }^{3,4}$ and frontal sinuses $^{5}$ are not that uncommon. A review of the literature shows that intranasal and maxillary sinus foreign bodies have been frequently reported especially among children. Among adults, however, they occur very rarely and are caused mostly by injury in an accident, trauma or coexisting mental disorders. ${ }^{6}$ In a large study of 420 cases of foreign bodies in the nasal cavity only one adult case, a homeless man with nasal myiasis was described. ${ }^{7}$ Unusual foreign bodies including buttons have been described very rarely in adults. ${ }^{8}$

Cases of endogenous foreign body like teeth or exogenous foreign body like gutta-percha, dental implants and dental materials ${ }^{9,10}$ are reported in national and international journals. Long term retention of sinus foreign bodies without sequel is rarely been reported. Sinusitis due to change in mucosal function and obstruction of sinus orifice by the foreign body is seen. ${ }^{11}$ Sinus malignancy through chronic stimulation of carcinogen from foreign bodies has also been reported. ${ }^{11-15}$

Uniqueness of the present case is in the fact that past history of facial trauma by a stone 30 years back was present which patient had also forgotten and patient presented with a history of only 15 days. History, examination and radiological findings suggested that the case may be of carcinoma maxilla. The biochemical analysis of the specimen showed the presence of silica and iron in high quantities as details given below:

Antral wall specimen: 1; Si: 515.8 ppm; P: nil; $\mathrm{Cl}$ : nil; S: nil; Ca: 6.71\%; V: 102.1 ppm; Mn: 40.8 ppm; Fe: 7,050.2 ppm; Cu: 15.1 ppm; Zn: 67.0 ppm; Sr: 407.3 ppm.

This favors toward long standing foreign body. It is noted that our patient lives independently and he is not known to have a mental illness. Thus, our case, to the best of our knowledge, represents one of the rare cases in the literature of such a large intramaxillary foreign body described in an adult without mental illness and without any antegrade history of trauma and without any nasal and sinus symptoms, which remained in situ for such a long time.

So, one should keep in mind, this type of rare possibility of long standing foreign body presenting as facial swelling. In all cases of maxillary swellings or sinusitis, detailed trauma history taking and facial scar evaluation should be done. CT and magnetic resonance imaging (MRI) of paranasal sinuses are helpful but should be read carefully and with a thorough clinical correlation to avoid misdiagnosis or nondetection in imaging.

Undoubtedly, even illnesses that are not complicated could prove difficulty for clinicians to diagnose. Clinicians should recognize the underlying causes that are responsible for symptoms of sinusitis or maxillary swelling. This case emphasizes the importance of history taking and a broad differential diagnosis.

\section{ACKNOWLEDGMENTS}

We wish to thank Department of Biochemistry, especially Dr Amit Tyagi, Assistant Professor, for providing the analytical details of the removed specimen.

\section{REFERENCES}

1. Christmas DA, Mirante JP, Yanagisawa E. An asymptomatic foreign body in a maxillary sinus ostium. Ear Nose Throat $\mathrm{J}$ 2003 Dec;82(12):905-906.

2. Ishiyama T. Maxillary antrolith: report of a case. Auris Nasus Larynx 1988;15(3):185-189.

3. Krennmair G, Lugmayr H, Lenglinger F. Radio-opaque structures in the lumen of the maxillary sinus--value of computerized tomography in the diagnosis of maxillary aspergillosis. Rofo 1993 Mar; 158(3):197-200.

4. Poll A, Wosiewitz U, Witting C. Spontaneous intra-antral rhinolith. A case study. HNO 1987 Dec;35(12):515-518.

5. Mori S, Lee K, Fujieda S, Kojima A, Saito H. Antrolithiasis in the frontal sinus. ORL J Otorhinolaryngol Relat Spec 2000 Nov-Dec;62(6):335-337.

6. Tay AB. Long-standing intranasal foreign body: an incidental finding on dental radiograph: a case report and literature review. Oral Surg Oral Med Oral Pathol Oral Radiol Endod 2000 Oct;90(4):546-549.

7. Figueiredo RR, Azevedo AA, Kos AO, Tomita S. Nasal foreign bodies: description of types and complications in 420 cases. Braz J Otorhinolaryngol 2006 Jan-Feb;72(1):18-23.

8. Pellacchia V, Moricca LM, Buonaccorsi S, Indrizzi E, Fini G. Unusual foreign body in the nasal cavity. J Craniofac Surg 2006 Nov;17(6):1176-1180.

9. Dimitrakopoulos I, Papadaki M. Foreign body in the maxillary sinus: report of an unusual case. Quintessence Int 2008 Sep;39(8):698-701.

10. Rodrigues MT, Munhoz ED, Cardoso CL, de Freitas CA, Damante JH. Chronic maxillary sinusitis associated with dental impression material. Med Oral Patol Oral Cir Bucal 2009 Apr; 14(4):E163-E166.

11. Kitanjir S, Tabuchi K, Hiraumi H. Transnasal bamboo foreign body lodged in the sphenoid sinus. Auris Nasus Larynx 2001 Nov;28(4):365-367.

12. Birnmeyer G. On late sequelae of metallic foreign bodies in the region of paranasal sinuses. Laryngol Rhinol Otol 1963 Nov;42:778-785.

13. Graces SM, Norris CW. Unusual frontal sinus foreign body. J Laryngol Otol 1972 Dec;86(12):1265-1268.

14. Hasegawa J, Wantabe K, Kunitomom, Yamauchi Y, Kurosaki S, Higa I, Aoki H, Yagi T. Foreign body in maxillary sinus-possible plastic tube: a case report. Auris Nasus Larynx 2003 Aug;30(3):299-301. 
15. Kelesidis T, Osman S, Dinerman H. An unusual foreign body as cause of chronic sinusitis: a case report. J Med Case Reports 2010;4:157.

\section{ABOUT THE AUTHORS}

\section{Ashish Katarkar}

Professor, Department of ENT, CU Shah Medical College, Surendranagar Gujarat, India

Correspondence Address: B-10, Doctor's Quarters, CU Shah Medical College, Surendranagar, Gujarat-363001, India, Phone: 02752-253088 09426454958,+91-8866148963, e-mail: ashishkatarkar@gmail.com ashishkatarkar@yahoo.com

\section{Modi Bhavesh}

Ex. Associate Professor, Department of ENT, CU Shah Medical College Surendranagar, Hanumant Hospital, Mahuva, Bhavnagar, Gujarat India

\section{Datt Modh}

Resident, Department of ENT, CU Shah Medical College, Surendranagar Gujarat, India

\section{Pankaj Shah}

Professor and Head, Department of ENT, CU Shah Medical College Surendranagar, Gujarat, India 